\title{
Tissue engineering-based cartilage repair with allogenous chondrocytes and gelatin-chondroitin-hyaluronan tri-copolymer scaffold: A porcine model assessed at 18, 24, and 36 weeks
}

\author{
Chih-Hung Chang ${ }^{\mathrm{a}, \mathrm{b}}$, Tzong-Fu Kuo ${ }^{\mathrm{d}}$, Chien-Cheng Lin ${ }^{\mathrm{a}}$, Cheng-Hung Chou ${ }^{\mathrm{a}}$, \\ Kuang-Ho Chen ${ }^{\mathrm{e}}$, Feng-Huei Lin ${ }^{\mathrm{a}, *}$, Hwa-Chang Liu ${ }^{\mathrm{a}, \mathrm{c}, *}$ \\ ${ }^{a}$ Institute of Biomedical Engineering, National Taiwan University, 7 Chung-Shan South Road, Taipei 100, Taiwan, ROC \\ ${ }^{\mathrm{b}}$ Department of Surgery, Division of Orthopedics, Far Eastern Memorial Hospital, Pan-Chiao 220, Taipei, Taiwan, ROC \\ ${ }^{c}$ Department of Orthopedic Surgery, National Taiwan University Hospital and Institute of Biomedical Engineering, National Taiwan University, \\ 7 Chung-Shan South Road, Taipei 100, Taiwan, ROC \\ ${ }^{\mathrm{d}}$ National Taiwan University Veterinary Hospital, Taipei, Taiwan \\ ${ }^{\mathrm{e}}$ The Mid-Formosa University of Sciences and Technology, Taichung, Taiwan
}

Received 9 June 2005; accepted 9 October 2005

Available online 8 November 2005

\begin{abstract}
We previously showed that cartilage tissue can be engineered in vitro with porcine chondrocytes and gelatin/chondoitin-6-sulfate/ hyaluronan tri-copolymer which mimic natural cartilage matrix for use as a scaffold. In this animal study, 15 miniature pigs were used in a randomized control study to compare tissue engineering with allogenous chondrocytes, autogenous osteochondral (OC) transplantation, and spontaneous repair for OC articular defects. In another study, 6 pigs were used as external controls in which full thickness (FT) and OC defects were either allowed to heal spontaneously or were filled with scaffold alone. After exclusion of cases with infection and secondary arthritis, the best results were obtained with autogenous OC transplantation, except that integration into host cartilage was poor. The results for the tissue engineering-treated group were satisfactory, the repair tissue being hyaline cartilage and/or fibrocartilage. Spontaneous healing and filling with scaffold alone did not result in good repair. With OC defects, the subchondral bone plate was not restored by cartilage tissue engineering. These results show that tri-copolymer can be used in in vivo cartilage tissue engineering for the treatment of FT articular defects.
\end{abstract}

(C) 2005 Published by Elsevier Ltd.

Keywords: Animal model; Cartilage tissue engineering; Gelatin; Hyaluronan; Chondroitin sulfate

\section{Introduction}

Although articular cartilage is a metabolically active tissue, the chondrocytes in the matrix have a relatively slow rate of turnover and the tissue itself lacks a blood supply to support repair and remodeling. Because of the limited capacity for spontaneous repair, minor injury to articular

\footnotetext{
${ }^{*}$ Corresponding author. Department of Orthopedic Surgery, National Taiwan University Hospital and Institute of Biomedical Engineering, National Taiwan University, 7 Chung-Shan South Road, Taipei, 100, Taiwan, ROC. Tel.: + $886223123456 x 5688$; fax: + 886223956988 .

E-mail addresses: double@ha.mc.ntu.edu.tw (F.-H. Lin), hcliu@ha.mc.ntu.edu.tw (H.-C. Liu).
}

cartilage can lead to progressive damage and degeneration. Recently, tissue engineering has emerged as a new method in which a combination of cells, scaffold, and bioactive agents is used to fabricate functional new tissue to replace damaged cartilage [1]. Many kinds of scaffold, both natural and synthetic, have been proposed for use in cartilage tissue engineering [2].

The mechanism by which the cell synthesizes and secretes extracellular matrix (ECM) and is then, in turn, regulated by the ECM is termed dynamic reciprocity [3]. In our previous in vitro study [4], we hypothesized that a tricopolymer formed from gelatin, chondroitin, and hyaluronan might mimic cartilage matrix and provide the 
necessary information for cell attachment to meet the requirement for dynamic reciprocity for cartilage tissue engineering. When this system was tested, chondrocytes were found to be uniformly distributed in the scaffold in spinner flask cultures, but less so in Petri dish cultures, ECM formation was seen on histological examination, and, in spinner flask cultures, chondrocytes retained their phenotype for at least 5 weeks and synthesized type II collagen, showing that gelatin/chondroitin sulfate/hyaluronan tri-copolymer has potential for use as a cartilage tissue engineering scaffold.

In the present study, miniature pigs were used to test the therapeutic effect of tissue engineering-based cartilage repair with allogenous chondrocyte-seeded tri-copolymer scaffold. Many treatment modalities, such as autogenous chondrocyte implantation, mosaicplasty, or marrow stimulating techniques, have been introduced to treat focal articular cartilage injury in young patients, but the results have been variable and the techniques have some limitations [5-8]. For tissue engineering to be considered as a realistic treatment for focal articular injury, it should be at least as good as the current treatment modalities. In this study, 15 sexually mature miniature pigs were used in a randomized control study to compare tissue engineering, autogenous osteochondral (OC) transplantation, and spontaneous healing for full thickness (FT) articular defects and OC defects.

Only a few studies on cartilage repair using tissue engineering have tested the effect of scaffold alone (without cell seeding) [8], although this is an absolute requirement. In addition, currently available scaffold matrices generally have suboptimal biocompatibility and biodegradability properties, and may therefore be expected to cause adverse reactions, which will need to be overcome during the course of healing. Transplanted cells may help in such a situation, but this needs to be proved experimentally [8]. Another six sexually mature pigs were therefore used in our study to check the biocompatibility and repair capacity of scaffold alone and to examine spontaneous repair of FT and OC defects.

\section{Materials and methods}

\subsection{Fabrication of scaffold}

The percentage dry weight of each component of hyaline cartilage is $15-20 \%$ type II collagen, $5-10 \%$ chondroitin sulfate, and $0.05-0.25 \%$ hyaluronan [9]. We therefore used these percentages to try to make a scaffold mimicking natural cartilage matrix from gelatin (a denatured collagen), chondoitin-6-sulfate, and hyaluronan, although the percentage of gelatin was slightly modified to increase scaffold pore size. Gelatin powder (0.5 g. G-2500; Sigma Co., St. Louis, USA), sodium hyaluronate (HA) $(5 \mathrm{mg}, 0.5 \mathrm{ml}$; Seikagaku Co., Tokyo, Japan), and chondroitin-6sulfate (C6S) powder (0.1 g; Sigma Co., St. Louis, USA) were mixed with $7 \mathrm{ml}$ of double distilled water and crosslinked for $2-3 \mathrm{~min}$ at $25^{\circ} \mathrm{C}$ using $2 \mathrm{ml}$ of $1 \%$ 1-ethyl-3-(3-dimethylamino-propyl)-carbodiimide (EDAC), the $\mathrm{pH}$ of the solution being 5-6. The solution was then frozen at $-20^{\circ} \mathrm{C}$ for $1 \mathrm{~h}$, frozen at $-70^{\circ} \mathrm{C}$ for $1 \mathrm{~h}$, and lyophilized for $72 \mathrm{~h}$. The dried scaffold was recrosslinked for $24 \mathrm{~h}$ at room temperature using $10 \mathrm{ml}$ of
$0.2 \%$ EDAC, then lyophilized for $72 \mathrm{~h}$. A tri-copolymer scaffold disc about $5 \mathrm{~cm}$ in diameter and $1 \mathrm{~cm}$ thick was produced and was cut into small scaffold cylinders $8 \mathrm{~mm}$ in diameter and 2 or $5 \mathrm{~mm}$ thick.

\subsection{Isolation of chondrocytes}

Full-thickness articular cartilage was harvested aseptically from adult porcine knee joints within $12 \mathrm{~h}$ after slaughter and chondrocytes were isolated by incubating the cartilage specimens for $12-16 \mathrm{~h}$ at $37^{\circ} \mathrm{C}$ in Dulbecco's modified Eagle's medium DMEM medium (DMEM; Hyclone Co., Logan, Utah, USA) containing $0.2 \%$ collagenase (Sigma Co., St. Louis, USA). The isolated chondrocytes were resuspended in phosphatebuffered saline, $\mathrm{pH}$ 7.4, washed, and counted using a hemocytometer. Chondrocyte viability was determined using Trypan blue dye exclusion.

\subsection{Culturing of chondrocyte-seeded tissue-engineered constructs}

Chondrocytes were expanded in a Petri dish in DMEM containing 10\% fetal bovine serum (Biological Industries Ltd, Kibbutz Beit Haemek, Israel), $1 \%$ penicillin/gentamicin (Sigma Co., St. Louis, USA), and $50 \mu \mathrm{g} /$ $\mathrm{ml}$ of L-ascorbic acid (Sigma Co., St. Louis, USA). At confluence, the cells were trypsinized and resuspended in DMEM at a concentration of about $5 \times 10^{7}$ cells $/ \mathrm{ml}$, and about $100 \mu \mathrm{l}$ of suspension was injected into each $2 \mathrm{~mm}$ thick scaffold cylinder for FT defects and about $250 \mu \mathrm{l}$ into each $5 \mathrm{~mm}$ thick scaffold cylinder for OC defects. The scaffold cylinders were then cultured in a spinner flask for 14 days before implantation in animals.

\subsection{Anesthesia and operation}

After approval by the ethical committee of the National Taiwan University, 21 Lee-Sung miniature pigs were used in the study. All pigs were sexually mature at the time of surgery.

All operations and interventions were performed under general anesthesia. The pigs were injected intramuscularly with atropine sulfate $(0.03 \mathrm{mg} / \mathrm{kg}$ body weight) before anesthesia to prevent salivary secretion. Zoletil $^{\mathbb{R}}(0.55-0.8 \mathrm{mg} / \mathrm{kg}$ body weight) was injected intramuscularly for pre-anesthesia, and then Citosol $^{\circledR}$ (Thiamylal) $(1.11-1.66 \mathrm{mg} / \mathrm{kg}$ body weight) was slowly injected intravenously for deep anesthesia.

Buprenorphine $(0.005-0.1 \mathrm{mg} / \mathrm{kg})$ or Flunixin $(1.0-2.2 \mathrm{mg} / \mathrm{kg})$ was injected intramuscularly as analgesic.

\subsection{Tissue engineering and internal controls}

Fifteen sexually mature Lee-Sung miniature pigs (eight male and seven female) underwent tissue engineering implantation with allogenous chondrocyte-seeded tri-copolymer scaffold covered with periosteum for $8 \mathrm{~mm}$ diameter FT articular defects $(2 \mathrm{~mm}$ deep) and OC defects $(5 \mathrm{~mm}$ deep), which were randomly assigned to the medial or lateral femoral condyle in the study knee. The periosteum was harvested from the proximal tibia in the same surgical approach, with the cambium layer facing the defect. In the contralateral knee, auto-transplantation in the medial or lateral condyle was performed by taking a $5 \mathrm{~mm}$ long autogenous OC graft from one condyle and transplanting it to the other condyle, the defect caused by harvesting serving as a spontaneous repair control. The condyles for the tissue engineering study and the internal control group were randomized (Table 1 and Fig. 1). No perioperative intravenous antibiotic was used. Antibiotic gel was applied to the wound under the dressing. The pigs were allowed free movement after surgery and were sacrificed in groups of 5 at 18,24, or 36 weeks after implantation.

\subsection{External controls}

This part of the study was designed to check the biocompatibility and repair capacity of the scaffold without cells and to observe spontaneous repair of FT and OC defects. Six sexually mature pigs (three male and 
Table 1A

Tissue engineering and internal control groups

\begin{tabular}{lllll}
\hline Pig no. & $1-3$ & $4-6,15$ & $7-9,13,14$ & $10-12$ \\
\hline R Medial & OC TE & A-T & FT TE & OC SR \\
R Lateral & FT TE & OC SR & OC TE & A-T \\
L Medial & A-T & OC TE & OC SR & FT TE \\
L Lateral & OC SR & FT TE & A-T & OC TE \\
\hline
\end{tabular}

Table 1B

External control groups

\begin{tabular}{lllll}
\hline Pig no. & 16,18 & 17 & 19,20 & 21 \\
\hline R Medial & FT P + S & FT SR & OC SR & OC P + S \\
R Lateral & OC P + S & OC SR & FT SR & FT P S \\
L Medial & FT SR & FT P + S & OC P + S & OC SR \\
L Lateral & OC SR & OC P + S & FT P + S & FT SR \\
\hline
\end{tabular}

$\mathrm{R}=$ right, $\mathrm{L}=$ left, $\mathrm{TE}=$ tissue engineering, $\mathrm{A}-\mathrm{T}=$ autotransplantation, $\mathrm{SR}=$ defect with spontaneous repair, $\mathrm{P}+\mathrm{S}=$ scaffold covered with periosteum without cells, $\mathrm{FT}=2 \mathrm{~mm}$ deep full thickness articular defect, $\mathrm{OC}=5 \mathrm{~mm}$ deep osteochondral defect. three female) were used. In each pig, an FT or OC defect was created in the medial or lateral condyle in both knees, then the defects in one knee were filled with tri-copolymer scaffold and covered with periosteum without cell seeding, while those in the contralateral knee were left as spontaneous repair controls. The location of the defects in the medial or lateral condyle or the left or right knee was again randomly assigned (Table 1). These pigs were sacrificed in groups of 2 at 18, 24, or 36 weeks after implantation.

\subsection{Day of sacrifice}

The pigs were sacrificed at 18 (nos. $1-5,20$, and 21), 24 (nos. 11-17), or 36 (nos. 6-10, 18, and 19) weeks after surgery. The specimens from the knee joints were embedded in paraffin and cut into $5 \mu \mathrm{m}$ slices, which were stained with hematoxylin and eosin stain for histological examination. Alcian Blue staining was used to evaluate the glycosaminoglycan (GAG) content.

\subsection{Evaluation of the animal study}

We chose to use the Pineda score for histological evaluation. However, the parameter of integration into host cartilage, which is also important [10], is not addressed in this scoring system, so we modified the Pineda
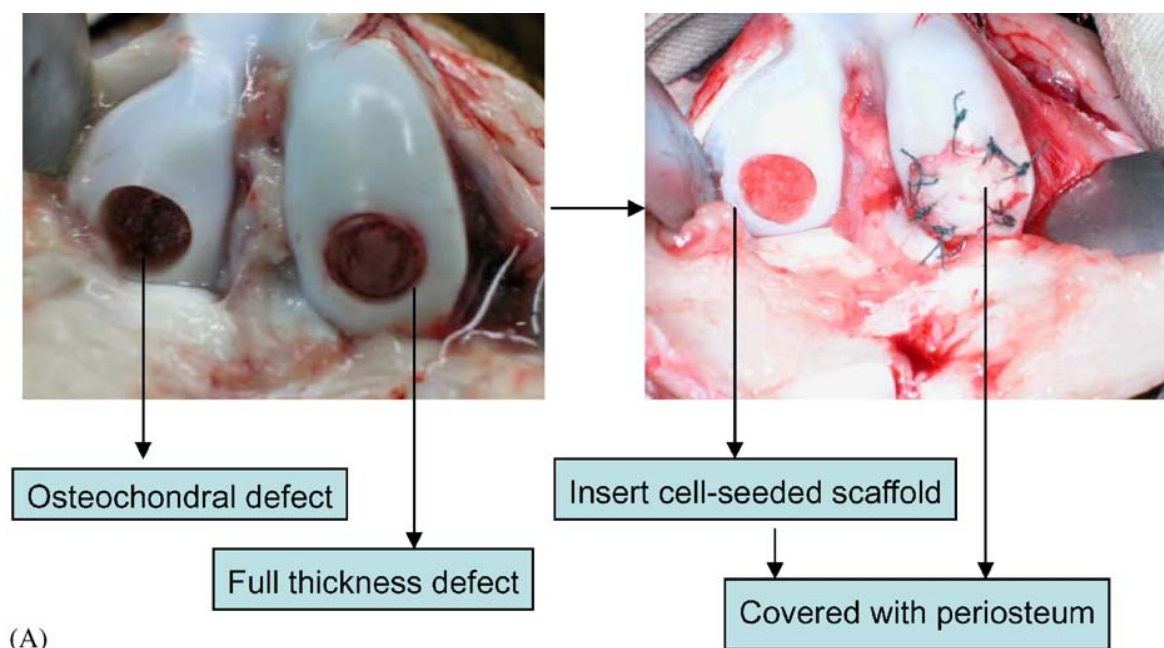

(A)

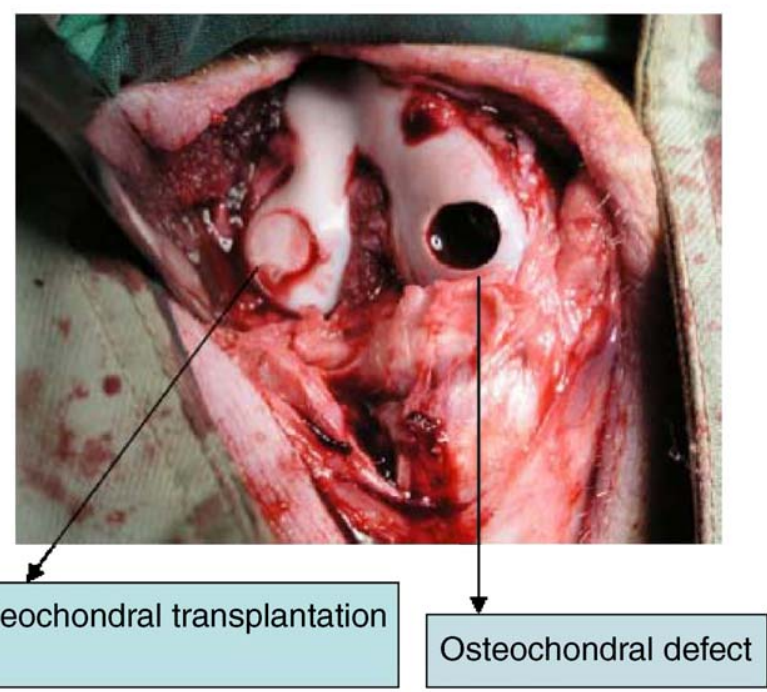

Fig. 1. (A) Surgical procedure in the study (tissue engineering) group. (B) Surgical procedure in the internal control group. 
score by including this parameter to evaluate the results of our animal study $[11,12]$. The total maximum score is 16 , with five parameters as subscores (Table 2). The score was evaluated by the first author (CHC) and Professor Tzong-Fu Kuo, the Superintendent of the National Taiwan University Veterinary Hospital (TFK).

Table 2

Modified pineda score

\begin{tabular}{lr}
\hline Parameters & \\
\hline Filling of defect & 1 \\
$125 \%$ & 0 \\
$100 \%$ & 1 \\
$75 \%$ & 2 \\
$50 \%$ & 3 \\
$25 \%$ & 4 \\
$0 \%$ & \\
Reconstruction of osteochondral junction & 0 \\
Yes & 1 \\
Almost & 2 \\
Not closed & \\
Matrix staining & 0 \\
Normal & 1 \\
Reduced staining & 2 \\
Significantly reduced staining & 3 \\
Faint staining & 4 \\
No staining & \\
Cell morphology & 0 \\
Normal & 16 \\
Mostly hyaline and fibrocartilage & 1 \\
Mostly fibrocartilage & 2 \\
Some fibrocartilage, but mostly non-chondrocytic cells & 3 \\
Non-chondrocytic cells only & 4 \\
Integration of donor with host adjacent cartilage & \\
Both edges integrated & \\
One edge integrated & \\
Neither edge integrated & \\
Total maximum & \\
& \\
& \\
&
\end{tabular}

\subsection{Statistics}

Statistical analysis was performed using a commercial program (Stat View, version 5.0, SAS Institute Inc., Heidelberg, Germany). ANOVA for balanced data from randomized complete block design was used to analyze differences in the modified Pineda score between the study and internal control groups. The effect of scaffold (without cell seeding) was tested in the external control group. One way ANOVA analysis was used to compare the study group and external control group.

\section{Results and discussion}

\subsection{Age and body weight}

After operation, all the animals tolerated bilateral arthrotomy well. The pigs were able to stand on all four limbs immediately after the end of anesthesia and were able to walk without limping a few days after the operation.

The age and body weight at surgery and sacrifice at 18,24 , and 36 weeks after implantation were analyzed (Table 3). For the study/internal control group, age and body weight at implantation in the three subgroups at the different sacrifice times were similar $(p>0.05)$. Age and body weight at implantation between the study/internal control group and external control group were significantly different $(p<0.05)$, with the external control group being younger and lighter.

\subsection{Gross appearance of the knee in the study/internal control and external control groups}

The gross appearance of the knee joints after sacrifice was classified as three grades. If the defect appeared fully repaired at the gross level with a smooth surface, this was denoted as "good" (Fig. 2), if it was partially repaired with a smooth surface, but not fully filled, this was denoted as "fair", while if it was not filled with cartilage at the gross level and if secondary osteoarthritis occurred, this was

Table $3 \mathrm{~A}$

Age and weight of the study and internal control groups (mean \pm SD)

\begin{tabular}{lllcc}
\hline Weeks & Age at implantation (months) & Age at sacrifice (months) & Body weight at implantation (kg) & Body weight at sacrifice (kg) \\
\hline 18 & $7.44 \pm 0.18$ & $11.64 \pm 0.18$ & $42.34 \pm 0.07$ & $52.94 \pm 10.10$ \\
24 & $7.57 \pm 2.64$ & $13.17 \pm 2.64$ & $46.7 \pm 16.14$ & $61.9 \pm 7.84$ \\
36 & $8.23 \pm 0.59$ & $16.61 \pm 0.57$ & $51.34 \pm 7.29$ & $79.1 \pm 19.16$ \\
\hline
\end{tabular}

Sample size: 5 pigs for each time of sacrifice.

Table 3B

Age and weight of external control groups $($ mean \pm SD)

\begin{tabular}{lllrr}
\hline Weeks & Age at implantation (months) & Age at sacrifice (months) & Body weight at implantation (kg) & Body weight at sacrifice (kg) \\
\hline 18 & $6.66 \pm 0.38$ & $10.87 \pm 0.38$ & $27.0 \pm 1.41$ & $41.95 \pm 2.89$ \\
24 & $4.63 \pm 0$ & $10.47 \pm 0$ & $29.25 \pm 0.92$ & $65.55 \pm 12.8$ \\
36 & $5.78 \pm 1.63$ & $14.15 \pm 1.63$ & $27.15 \pm 3.75$ & $65.3 \pm 15.98$ \\
\hline
\end{tabular}

Sample size: 2 pigs at each time of sacrifice. 
graded as "poor". The results are shown in Fig. 3. ANOVA for balanced data from randomized complete block design analysis showed there was a significant difference between the groups treated with OC tissue engineering or auto-transplantation compared to spontaneous healing of an OC defect $(p<0.05)$. Condyles treated with tissue engineering for FT defects were slightly better than those undergoing spontaneous repair of an OC defect $(p=0.0897)$. There was no significant difference between the groups receiving tissue engineering for FT or OC defects, between those receiving FT tissue engineering or

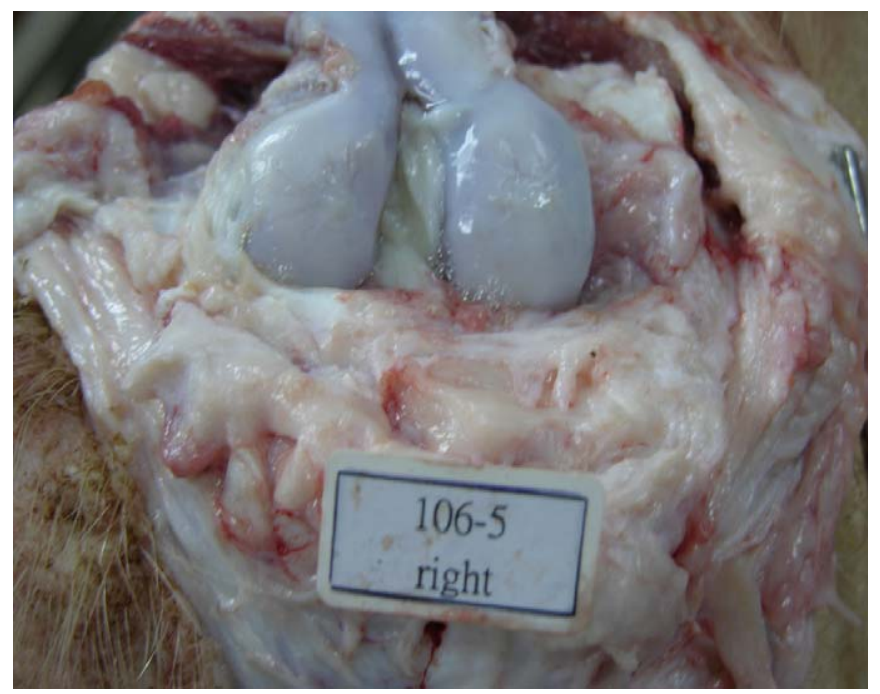

Fig. 2. Result with good gross appearance. auto-transplantation, and between those receiving OC tissue engineering or auto-transplantation.

In condyles in which the defect was filled with scaffold and covered with periosteum, scarring fibrous tissue and secondary osteoarthritis were seen. In condyles with spontaneous repair of OC defects, collapse of the articular surface and the growing of adjacent cartilage into the defect were seen, giving the appearance of a fold. In condyles with spontaneous repair of FT defects, the results were fibrocartilage-like tissue without collapse, but without full resurfacing (Fig. 4).

\subsection{Histological characteristics of the different groups}

\subsubsection{Tissue engineering of full-thickness articular defects}

In those condyles treated with tissue engineering for FT defects showing good or fair gross results, histological examination showed hyaline cartilage or fibrocartilage. Most of the engineered cartilage (both hyaline and fibrocartilage) showed good integration into the subchondral bone and adjacent host cartilage and the subchondral bone plates were intact. The hyaline cartilage showed columnar organization (Fig. 5A); in some areas, proliferating cell clusters were noted, indicating new growth of engineered cartilage tissue. In cases with fibrocartilage repair, there was a fibrous structure in the matrix and cell organization was more irregular (Fig. 5B).

In those condyles treated with FT tissue engineering showing poor gross results, histological examination also showed poor results. The subchondral bone plates were eroded, and the defect sites were filled with fibrous tissue with vascular invasion.

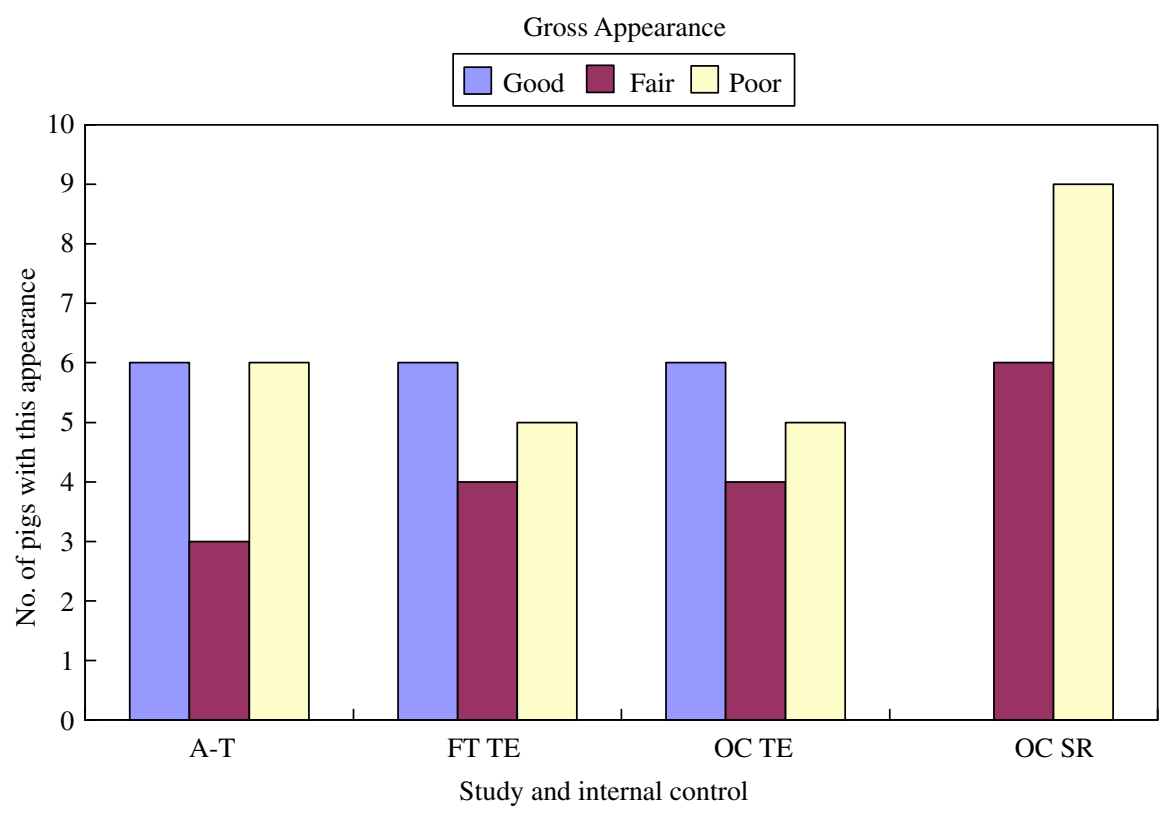

Fig. 3. Distribution of the gross appearance results in the study/internal control group (sample size $=15$ pigs). (A-T = autotransplantation; FE $\mathrm{TE}=$ tissue engineering treatment of a $2 \mathrm{~mm}$ deep full thickness articular defect; OC TE $=$ tissue engineering treatment in $5 \mathrm{~mm}$ deep osteochondral defect; OC SR = spontaneous repair of $5 \mathrm{~mm}$ deep osteochondral defect.) 

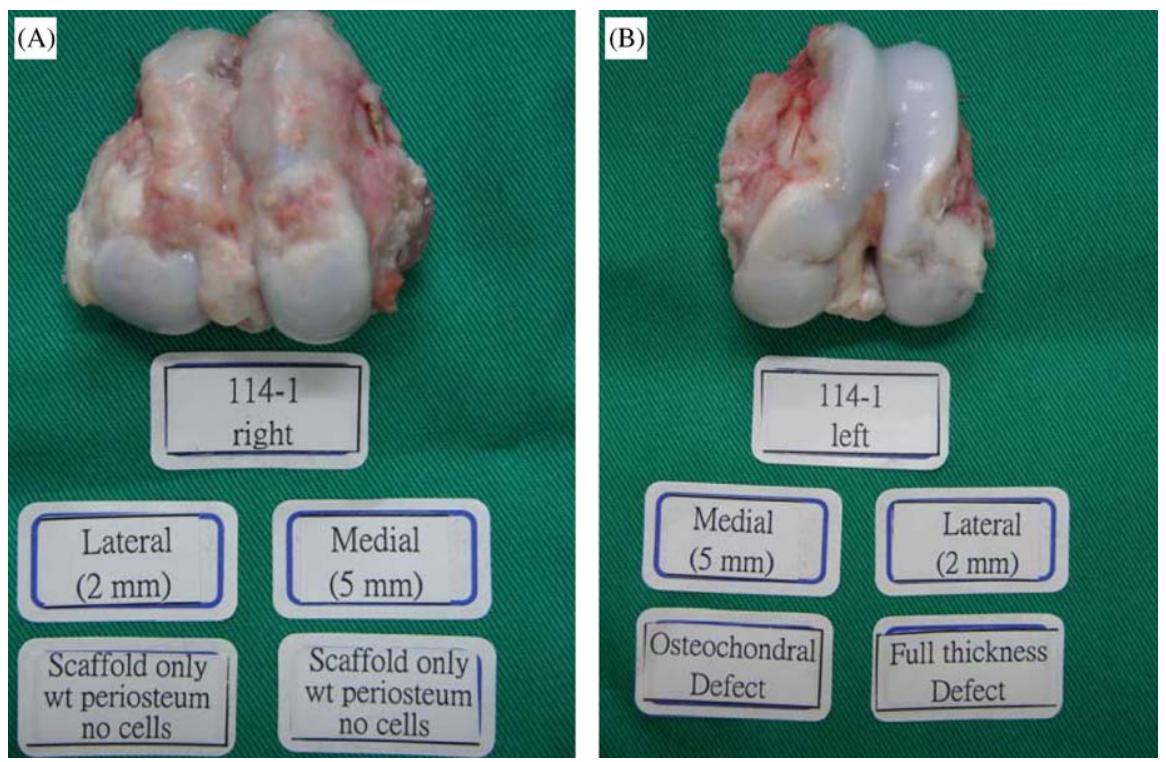

Fig. 4. Gross appearance of the external control groups. (A) Defects filled with scaffold and covered with periosteum showed scarring fibrous tissue and secondary osteoarthritis. (B) Spontaneous repair of an osteochondral defect showing collapse of the articular surface and growing of adjacent cartilage into the defect, which looks like a fold. Spontaneous repair of a full thickness defect showing fibrocartilage-like tissue without collapse, but not fully resurfaced.
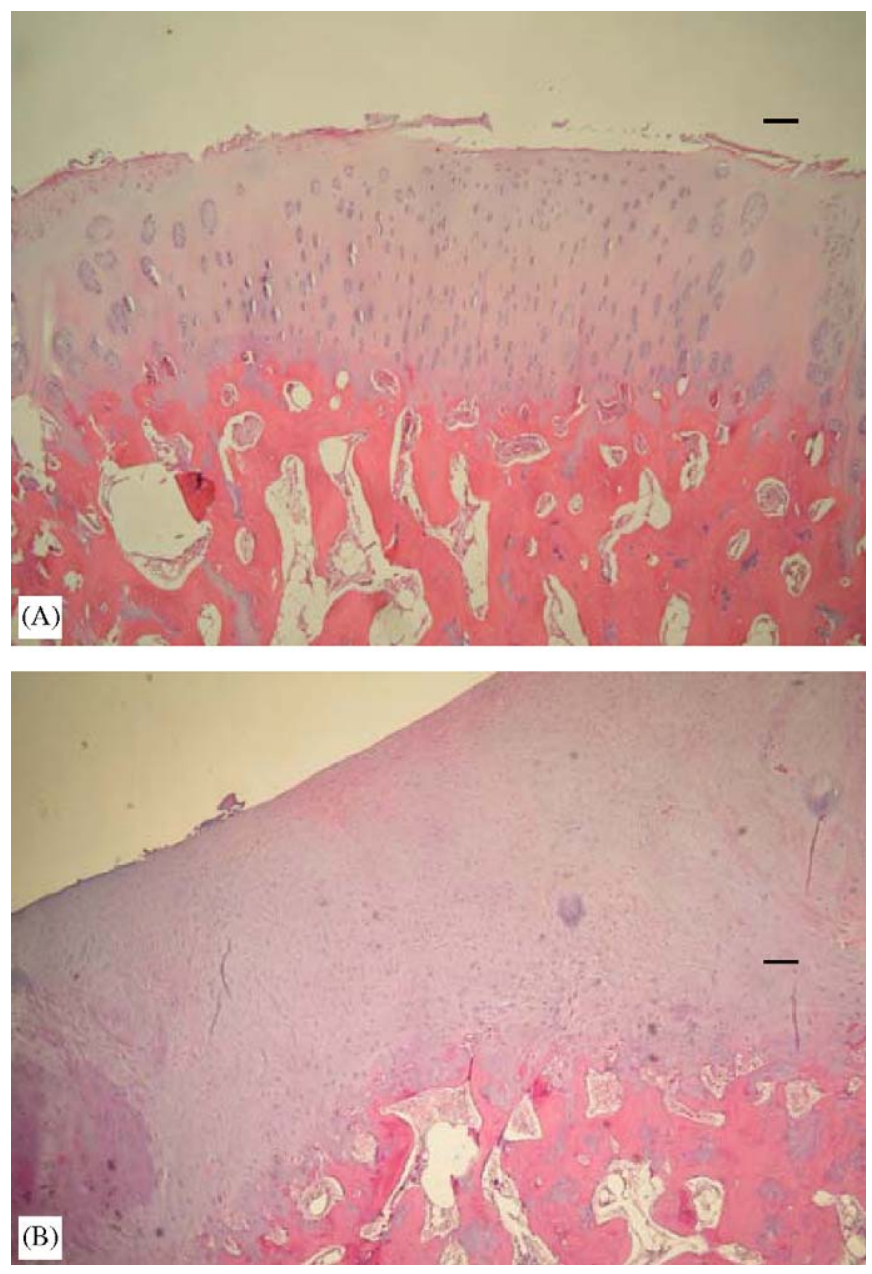

Fig. 5. Hematoxylin-eosin-stained paraffin sections of FT tissue engineered defects. (A) Hyaline cartilage (original magnification, $\times 40$; bar, $200 \mu \mathrm{m}$ ); (B) Fibrocartilage (original magnification, $\times 40$; bar, $200 \mu \mathrm{m}$ ).

\subsubsection{Tissue engineering of osteochondral defects}

The tissue engineering results in condyles with OC defects were quite variable. The repair tissue was hyaline cartilage, fibrocartilage, and fibrous tissue. Most condyles were repaired with fibrocartilage, while some were repaired with hyaline cartilage (Fig. 6A and B). All the repaired tissues were well integrated into the adjacent host cartilage; however, the subchondral bone plates were not restored, which is compatible with a previous report on cartilage tissue engineering with allogenous chondrocytes [13]. In some condyles, the repair tissue was mixed fibrocartilage and hyaline cartilage, with some of the central areas being occupied by fibrous tissue (Fig. 6C); we believe this is probably due to ineffective seeding of cells into the central part of the scaffold.

In the condyles with poor gross results, histological examination also showed poor results. The subchondral bone plates were eroded, and the defect sites filled with fibrous tissue with vascular invasion.

\subsubsection{Auto-transplantation}

Except in a few cases which showed some degeneration or osteoarthritic change, most of the condyles treated with auto-transplantation showed good results. At the gross level, the transplanted margin was still visible. As shown in Fig. 7A, on histological examination, the transplanted tissues were well integrated into host subchondral bone, and the morphology was normal hyaline cartilage. However, the margin adjacent to host cartilage was not integrated and most of the specimens showed large gaps between the two. Cell loss and loss of GAG at this junction area were seen. As shown in Fig. 7B, the cells formed clusters, indicating an effort to repair the gap; however, 

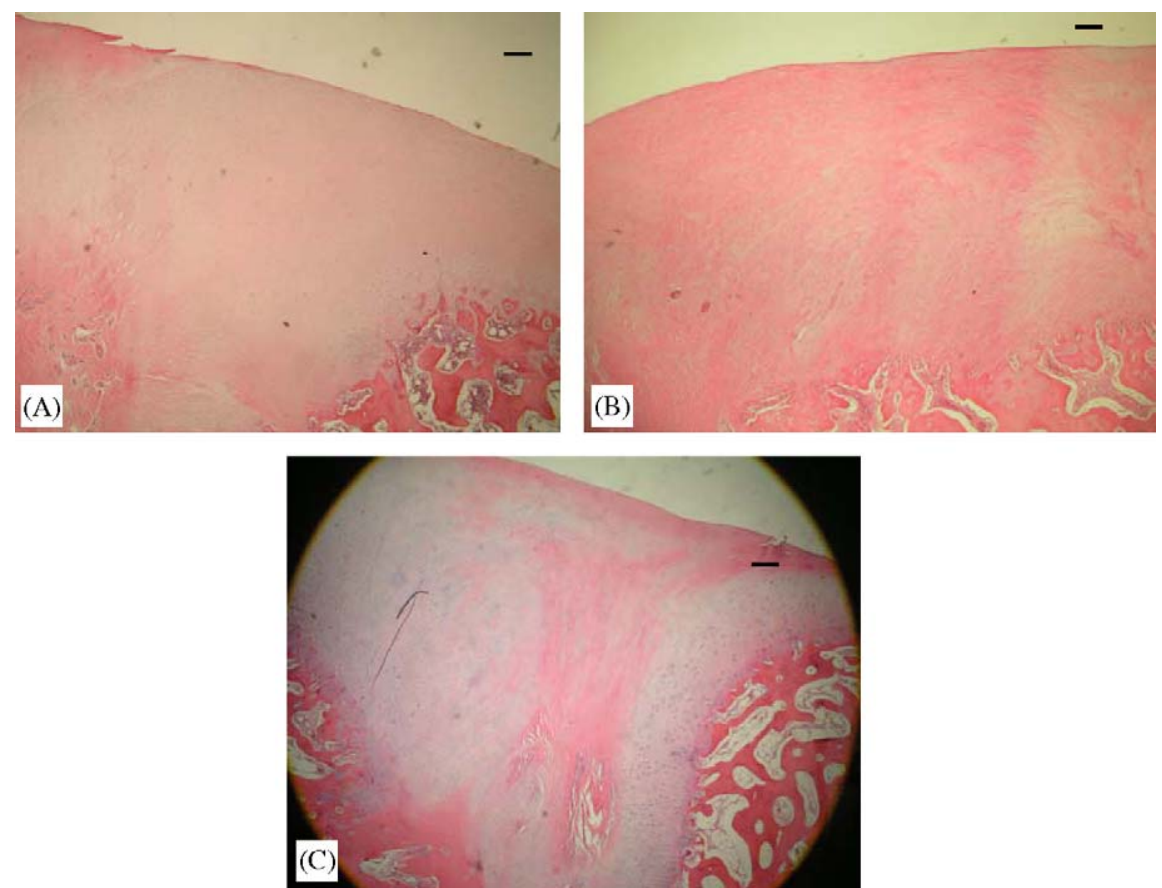

Fig. 6. Hematoxylin-eosin stained paraffin sections of OC tissue engineered defects.. (A) Hyaline cartilage formation (original magnification, $\times 40$; bar, $200 \mu \mathrm{m}$ ); (B) Fibrocartilage formation (original magnification, $\times 100$; bar, $500 \mu \mathrm{m}$ ); (C) OC TE with central fibrous tissue (original magnification, $\times 20$; bar, $100 \mu \mathrm{m})$.

these cell clusters were confined within the surrounding matrix and integration never occurred. At the top of the gap, some repair with fibrous tissues was noted. Some destruction of the subchondral bone plate at the junction area was also noted (Fig. 7A).

\subsubsection{Spontaneous repair of osteochondral defects in the internal and external control groups}

Some of the OC defects undergoing spontaneous repair showed collapse of the adjacent host cartilage with formation of subchondral cysts filled with fibrous tissue (Fig. 8A). Some showed filling with fibrous tissue with vascular invasion and the surface were level with, or stood proud of, the adjacent cartilage (Fig. 8B). Only two condyles showed repair with fibrocartilage. The subchondral bone plates were not restored in any of the condyles with OC defects (Fig. 8).

\subsubsection{Spontaneous repair of full-thickness defects \\ in the external control groups}

The full-thickness defects undergoing spontaneous repair in the external control groups showed better repair than the OC defects. Some condyles were filled with delaminated fibrous tissue (Fig. 9A), while others were filled with fibrocartilage or mixed hyaline and fibrocartilage (Fig. 9B). The subchondral bone plates at the base of the defects were well preserved, but those at the margin of the defects were partially destroyed. The repaired tissues showed delamination or fissuring (Fig. 9A and B).

\subsubsection{The repair response to scaffold biomaterial without cell seeding}

The effects of scaffold biomaterial alone were tested in the external control groups using FT and OC defects filled with scaffold and covered with periosteum.

In the OC defects filled with scaffold, some showed repair tissue consisting of a mixture of hyaline, fibrocartilage, and fibrous tissue and the surface stood proud of the adjacent cartilage. Others showed repair tissue consisting of a mixture of fibrocartilage and fibrous tissue and the surface was irregular and delaminated with vascular invasion (Fig. 10). The subchondral bone plates were not restored in any of the defects and some cases even showed subchondral cyst formation.

In the FT defects filled with scaffold, some showed bizarre and irregularly shaped repair tissue, consisting of a mixture of fibrous tissue, fibrocartilage, and clusters of chondrocytes. Some showed bizarre and irregular shaped fibrous tissue with vascular invasion (Fig. 11). Most areas of the subchondral bone plates were preserved, but some showed erosion of subchondral bone and filling with fibrous tissue. In one condyle from an animal sacrificed at 18 weeks after surgical implantation, some retained scaffold was still visible, indicating that the scaffold can last at least 18 weeks before being totally degraded.

\subsubsection{Semi-quantitative histological evaluation using the modified pineda score}

3.3.7.1. Parameters and statistical analysis (Table 4).

The sum of the scores for all five parameters was taken as 

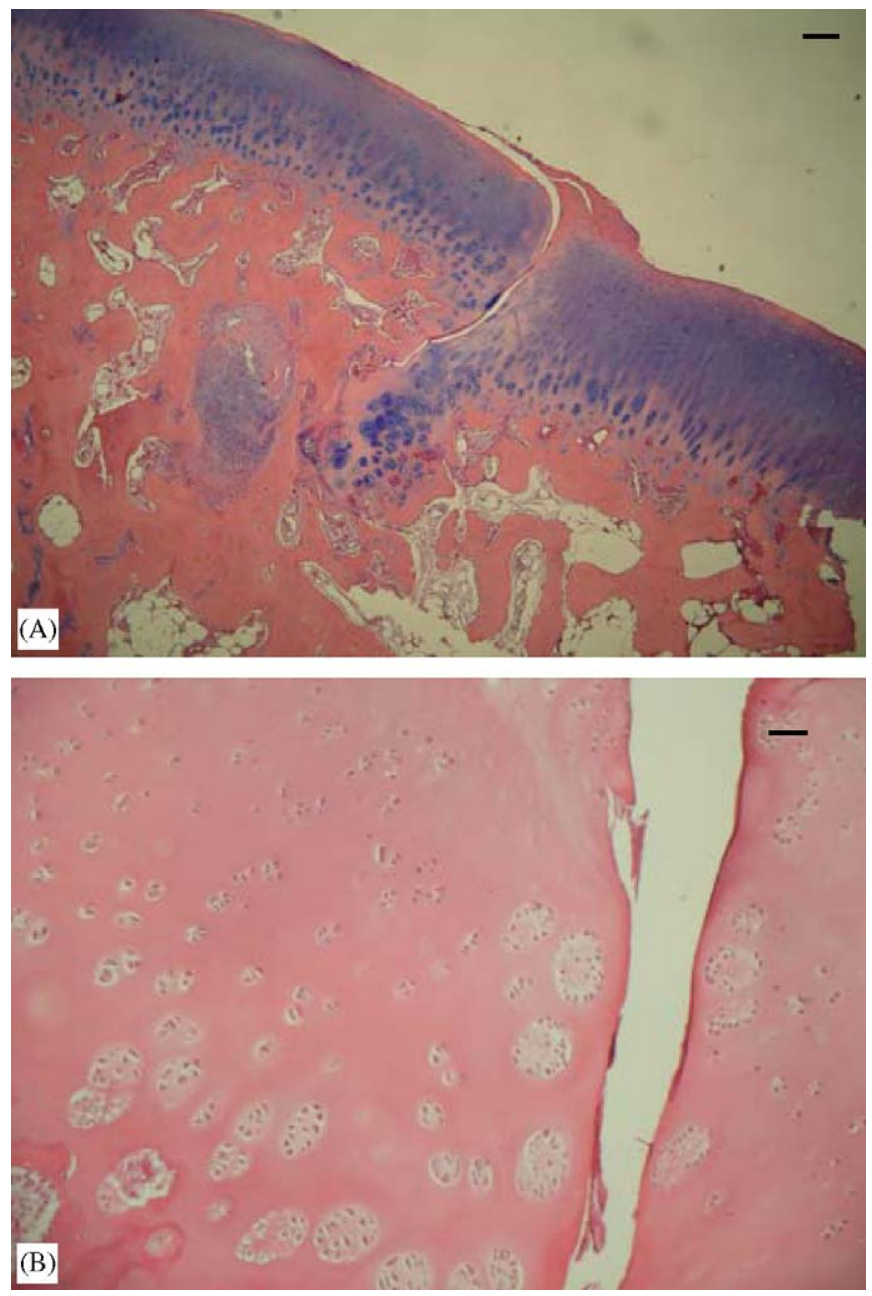

Fig. 7. Alcian blue-stained paraffin sections of a condyle treated with auto-transplantation. (A). There is good integration into the subchondral bone. The junction area shows loss of glycosaminoglycan (less blue stain) and some destruction of the subchondral bone plate. The surface of the junction area is covered with some fibrous tissue (original magnification, $\times 40$; bar, $200 \mu \mathrm{m}$ ). (B) Cell cluster formation at the junction area. There is no integration into host cartilage (original magnification, $\times 100$; bar, $500 \mu \mathrm{m})$.

the "total score", which represents the overall repair quality in each group (Fig. 12).

Filling was best in the auto-transplantation group, followed by the FT tissue engineering group, the OC tissue engineering group, and finally the spontaneous repair group.

The reconstitution and remodeling of the OC junction under the repair tissue was best in condyles treated with auto-transplantation, followed by FT tissue engineering, OC tissue engineering, and finally with spontaneous repair.

Alcian blue staining was used to evaluate the GAG content of the repair tissue compared to the neighborhood host cartilage. Staining of the repair tissue was best in condyles treated with auto-transplantation, followed by FT tissue engineering, OC tissue engineering and finally spontaneous repair.
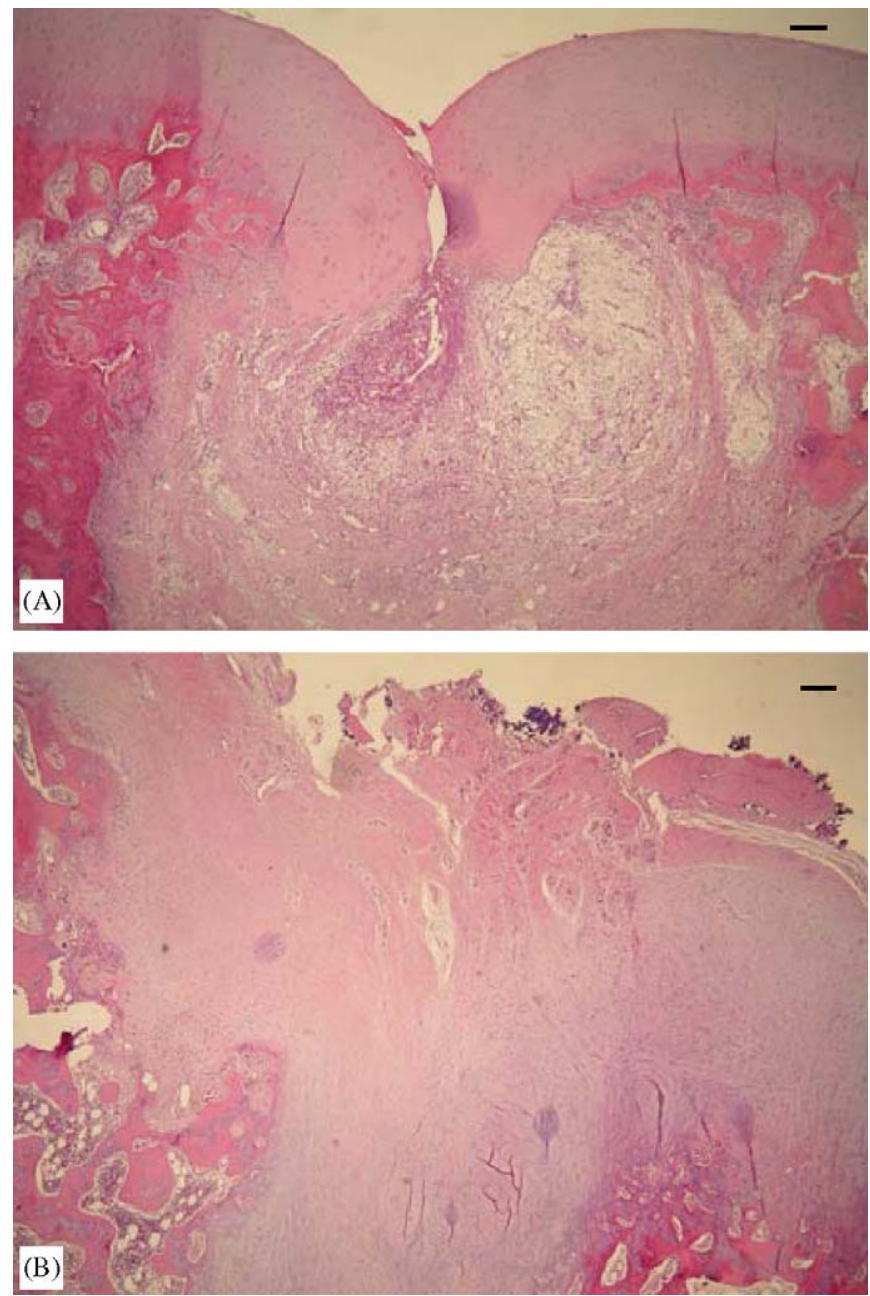

Fig. 8. Hematoxylin-eosin stained paraffin sections of a condyle with spontaneous repair of an osteochondral defect. (A) The adjacent cartilage is collapsed and subchondral cyst formation is noted (original magnification, $\times 40$; bar, $200 \mu \mathrm{m}$ ). (B) The repair fibrous tissue stands proud of the surface. The subchondral bone is not restored with fibrocartilage filling (original magnification, $\times 40$; bar, $200 \mu \mathrm{m}$ ).

Most of the repair tissues in condyles treated with autotransplantation was hyaline cartilage. Some of the FT tissue engineered repair tissue showed hyaline cartilage with clusters of proliferating chondrocytes, while others showed fibrocartilage formation. Most of the repair tissue in the $\mathrm{OC}$ tissue engineering group was a mixture of hyaline and fibrocartilage, while other showed only fibrocartilage. The central core area of the defect in the OC tissue engineered group sometimes showed fibrocartilage or fibrous tissue, which may be caused by insufficient cell seeding into the central part of the scaffold. Condyles undergoing spontaneous repair showed the worst repair tissue, most having fibrous tissue with vascular invasion. In both the study and internal control groups, condyles showing osteoarthritis all showed poor cell morphology in the repair tissue.

Although the auto-transplantation group showed excellent results in total score and other subscore parameters, it showed serious problems in terms of integration into host 

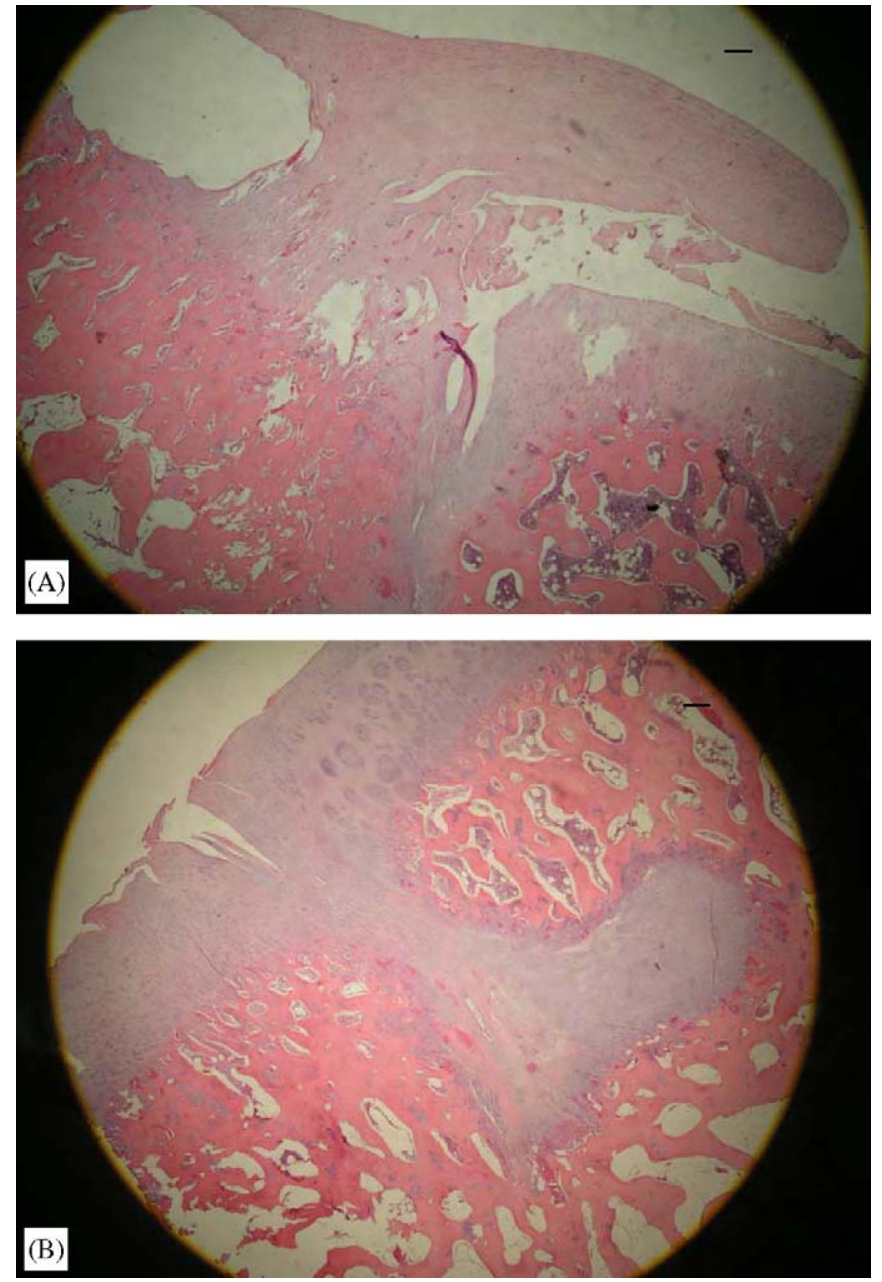

Fig. 9. Hematoxylin-eosin stained paraffin sections showing spontaneous repair of full thickness defects. (A) Delaminated fibrous repair tissue standing proud of the adjacent cartilage, a preserved subchondral bone plate at the base of the defect, and destruction of subchondral bone at the margin (original magnification, $\times 20$; bar, $100 \mu \mathrm{m}$ ). (B) Repair tissue consisting of a mixture of hyaline and fibrocartilage, with fissuring and degeneration. Destruction of subchondral bone at the margin is also noted (original magnification, $\times 20$; bar, $100 \mu \mathrm{m}$ ).

cartilage. Although many cell clusters were noted at the junction area, no real integration occurred.

ANOVA analysis of the results for the different time points after implantation for each group showed no obvious influence of time from implantation on the total score (data not shown), so, for further analysis, the results for the different time points were combined. Statistical analysis of the results (Table 4) showed no significant difference in total score between the groups receiving tissue engineering for FT and OC defects or between the FT tissue engineering group and the auto-transplantation group. However, the results for the auto-transplantation group were better than those for the $\mathrm{OC}$ tissue engineering group. The results for the FT tissue engineering, OC tissue engineering, and auto-transplantation groups were all better than those for the spontaneous repair group.

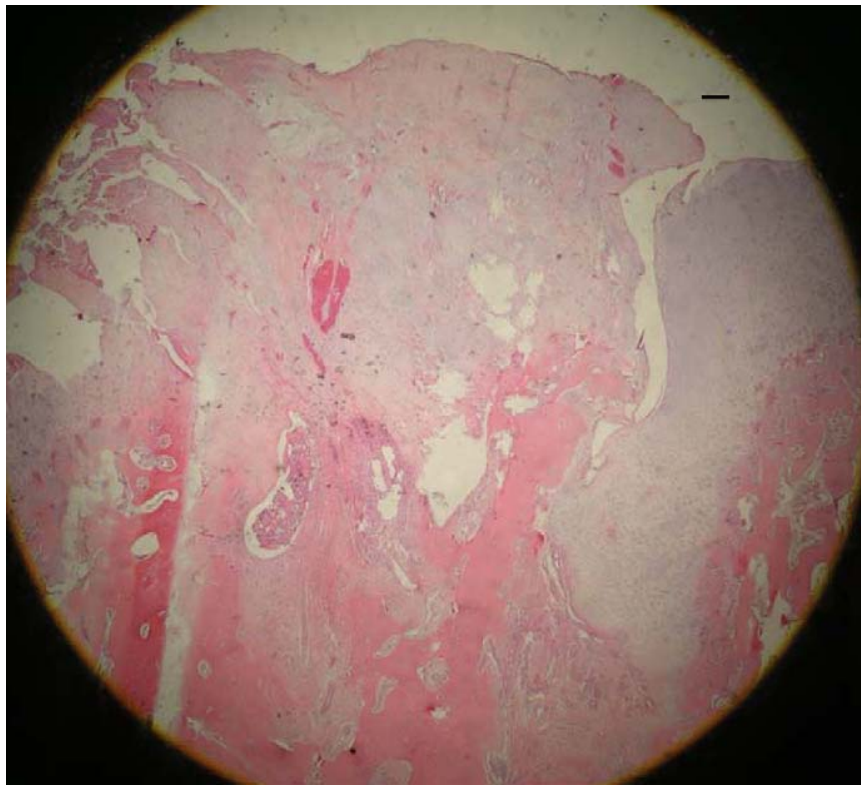

Fig. 10. Hematoxylin-eosin-stained paraffin sections of osteochondral defects filled with scaffold without cell seeding and covered with periosteum. Repair tissues are a mixture of fibrocartilage and fibrous tissue. The surface is irregular and delaminated with vascular invasion (original magnification, $\times 20$; bar, $100 \mu \mathrm{m}$ ).

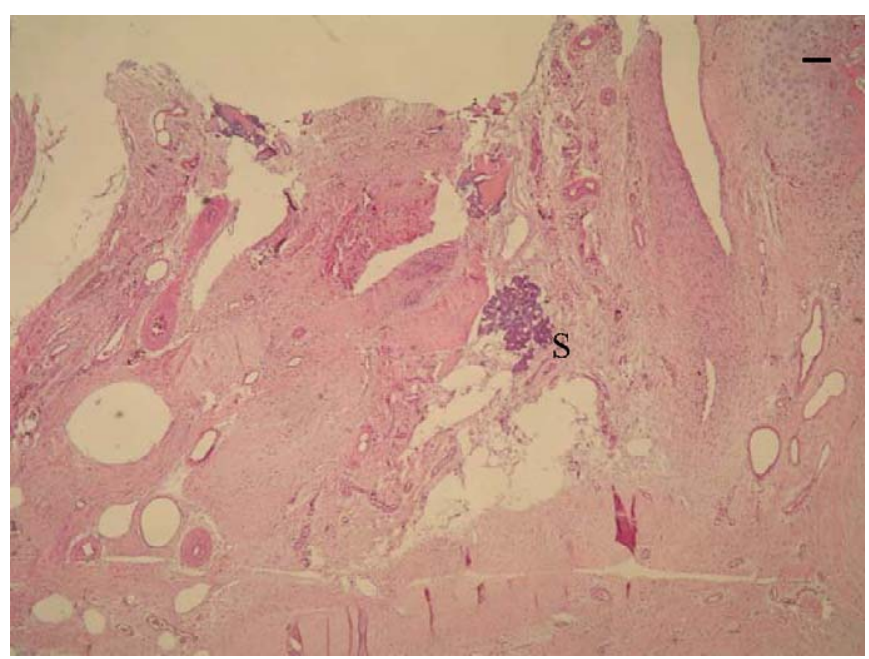

Fig. 11. Hematoxylin-eosin-stained paraffin sections of full thickness defects filled with scaffold without cell seeding and covered with periosteum. Repair tissue with bizarre and irregularly shaped fibrous repair tissue with vascular invasion. S: retained scaffold (original magnification, $\times 40$; bar, $200 \mu \mathrm{m})$.

Statistical analysis of all the parameters is also shown in Table 4. Generally there is less significant difference between the FT and OC tissue engineering groups, while auto-transplantation gave better results. The results for the FT tissue engineering, OC tissue engineering, and autotransplantation groups were all better than those for the spontaneous repair group in most of the parameters, while auto-transplantation gave the worst integration score. 


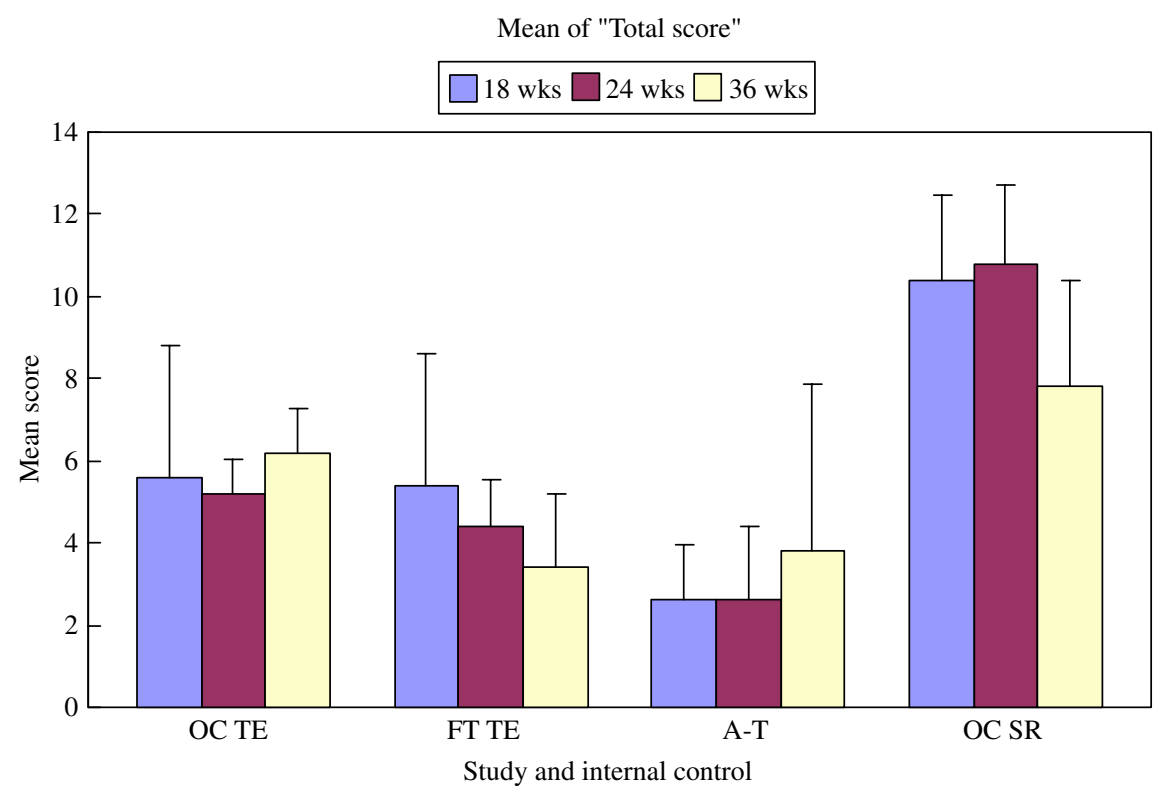

Fig. 12. Comparison of the modified Pineda scores in the study and internal control groups (sample size $=15$ pigs). (OC TE $=5 \mathrm{~mm}$ deep osteochondral defect treated with tissue engineering; FT TE $=2 \mathrm{~mm}$ deep full thickness articular defect treated with tissue engineering; A-T = auto-transplantation; OC $\mathrm{SR}=5 \mathrm{~mm}$ deep osteochondral defect for spontaneous repair.)

Table 4

Statistic analysis for the Pineda score (ANOVA for balanced data from randomized complete block design)

\begin{tabular}{|c|c|c|c|c|c|c|}
\hline & Total score & Filling score & Subchondral score & Matrix score & Cell score & Integration score \\
\hline OC TE vs. FT TE & 0.1199 & 0.241 & $0.0002 *$ & 0.6777 & 0.529 & 0.5907 \\
\hline OC TE vs. OC SR & $<0.0001 *$ & $0.0106^{*}$ & 0.2463 & $0.0001 *$ & $<0.0001^{*}$ & 0.1827 \\
\hline OC TE vs. A-T & $0.0018^{*}$ & $0.0435^{*}$ & $<0.0001^{*}$ & $0.0425^{*}$ & $<0.0001^{*}$ & $<0.0001^{*}$ \\
\hline FT TE vs. OC SR & $<0.0001^{*}$ & $0.0004^{*}$ & $<0.0001^{*}$ & $<0.0001^{*}$ & $0.0002 *$ & 0.0647 \\
\hline FT TE vs. Auto-transplant & 0.0866 & 0.3774 & 0.085 & 0.1015 & $<0.0001^{*}$ & $<0.0001^{*}$ \\
\hline OC defect vs. Auto-transplant & $<0.0001 *$ & $<0.0001^{*}$ & $<0.0001 *$ & $<0.0001^{*}$ & $<0.0001^{*}$ & $0.0005^{*}$ \\
\hline
\end{tabular}

$\mathrm{TE}=$ tissue engineering, $\mathrm{A}-\mathrm{T}=$ autotransplantation, $\mathrm{SR}=$ defect with spontaneous repair, $\mathrm{P}+\mathrm{S}=$ scaffold covered with periosteum without cells, $\mathrm{FT}=2 \mathrm{~mm}$ deep full thickness articular defect, $\mathrm{OC}=5 \mathrm{~mm}$ deep osteochondral defect, ${ }^{*}=$ statistically significant.

\subsubsection{Comparison of the external control group and the} study group. Only a few studies have tested scaffold alone without cell seeding [8]. To make a comparison, the depth of the defect should be comparable, so we compared (1) the results of OC and FT tissue engineering in the study group, (2) the filling of OC and FT defects with scaffold alone covered with periosteum in the external group; and (3) spontaneous repair of $\mathrm{OC}$ and FT defects in the contralateral knee of the external group. Basically, these three groups have a similar depth of defect, and are comparable. One way ANOVA was used to analyze differences between the study and external control groups. The results are shown in Fig. 13 and Table 5.

With the FT defects, there were significant differences in total score, subchondral score, matrix score, and integration score between the tissue engineering- and scaffoldtreated groups, but there were no significant differences between the tissue engineering-treated and spontaneous repair groups. With the OC defects, there were significant differences in total score and cell score between the tissue engineering- and scaffold-treated groups and significant differences in total score, filling score, matrix score, and cell score between the tissue engineering-treated and spontaneous repair groups.

In the FT defect groups, the repair results were best with tissue engineering, followed by spontaneous repair and FT tissue engineering, and finally by filling with scaffold alone.

In the OC defect group, the repair results were best with tissue engineering, followed by scaffold alone, then spontaneous repair.

\section{Discussion}

Traditionally, cartilage tissue engineering studies have used poly-glycolic acid, poly-L-lactic acid, or a copolymer of the two to make scaffold [reviewed in 14]. However, these materials have certain shortcomings in that they are non-biological and lack informational structure, such as the Arg-Gly-Asp sequence for cell attachment, and their degradation products, e.g., glycolic acid and lactic acid, are 


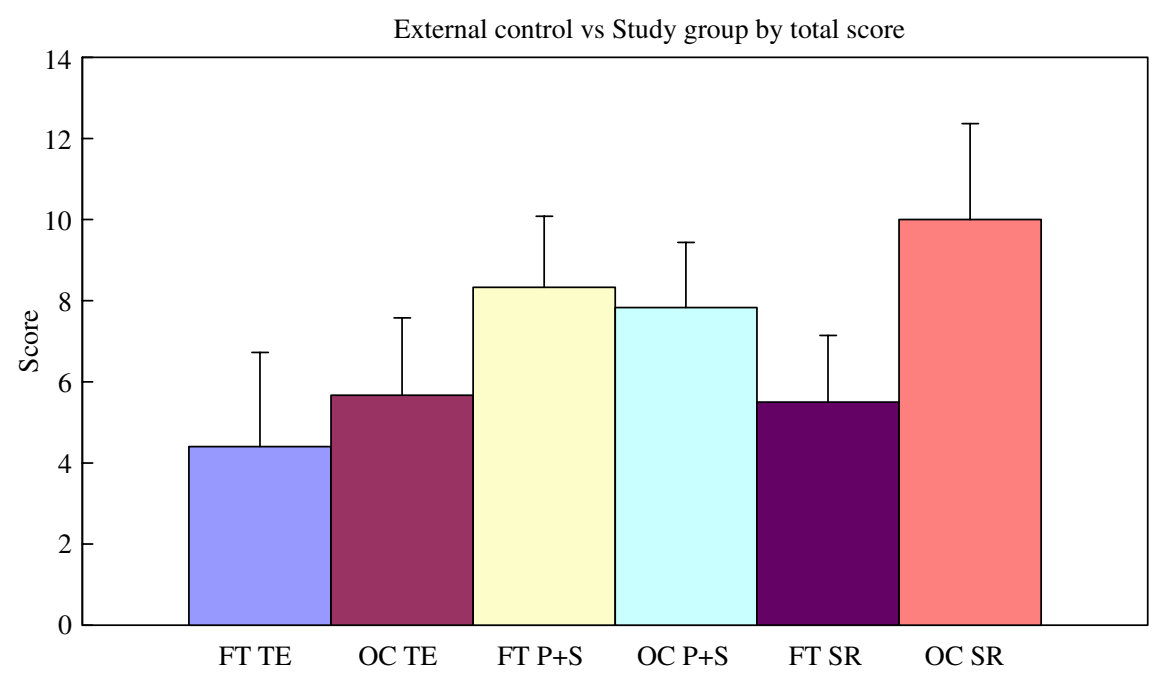

Fig. 13. Comparison of the total scores in the external control group and study group (sample size: study $=15$ pigs, external control $=6$ pigs). (OC $\mathrm{TE}=5 \mathrm{~mm}$ deep osteochondral defect treated with tissue engineering; FT TE $=2 \mathrm{~mm}$ deep full thickness articular defect treated with tissue engineering; FT $\mathrm{P}+\mathrm{S}=2 \mathrm{~mm}$ deep full thickness articular defect filled with scaffold and cover with periosteum with no cell seeding; OC $\mathrm{P}+\mathrm{S}=5 \mathrm{~mm}$ deep osteochondral defect filled with scaffold and cover with periosteum with no cell seeding; FT SR $=2 \mathrm{~mm}$ deep full thickness articular defect for spontaneous repair; OC SR $=5 \mathrm{~mm}$ deep osteochondral defect for spontaneous repair.)

Table 5

Comparison of the external control group and the study group (ANOVA)

\begin{tabular}{lccllccc}
\hline & Total score & Filling score & Subchondral score & Matrix score & Cell score & Integration score & Gross appearance \\
\hline FT TE vs. FT P + S & $0.001^{*}$ & 0.097 & $0.003^{*}$ & $0.039^{*}$ & 0.083 & $0.046^{*}$ & 0.462 \\
FT TE vs. FT SR & 0.306 & 0.417 & 0.210 & 0.843 & 0.165 & 0.433 & 0.776 \\
OC TE vs. OC P+S & $0.025^{*}$ & $>0.999$ & 0.750 & 0.075 & $0.002^{*}$ & 0.813 & 0.420 \\
OC TE vs. OC SR & $<0.001^{*}$ & $0.023^{*}$ & 0.372 & $0.004^{*}$ & $<0.001^{*}$ & 0.813 & 0.679 \\
\hline
\end{tabular}

$\mathrm{TE}=$ tissue engineering, $\mathrm{SR}=$ defect with spontaneous repair, $\mathrm{P}+\mathrm{S}=$ scaffold covered with periosteum without cells, FT $=2 \mathrm{~mm}$ deep full thickness articular defect, $\mathrm{OC}=5 \mathrm{~mm}$ deep osteochondral defect, ${ }^{*}=$ statistically significant.

acidic and lower the $\mathrm{pH}$ around tissue after in vivo implantation, which may cause severe inflammation [15]. Since our previous in vitro study proved that gelatin/ chondroitin sulfate/hyaluronan tri-copolymer can serve as a good scaffold for cartilage tissue engineering, with cartilage tissue formation and good biocompatibility [4], this tri-copolymer deserves to be tested in vivo as a candidate for cartilage tissue engineering.

Several different animals species, including rabbits, goats, sheep, horses, and miniature pigs, have been used in articular cartilage defect studies [16]. Animal models play important roles in the preclinical screening and assessment of potential problems of new cartilage repair procedures and can be used to determine whether a specific method can restore an articular surface and to compare methods of restoring articular surface in vivo [17]. There are some problems with the commonly used experimental small animals. In the human knee, the thickness of the hyaline articular cartilage is approximately $1.65-2.65 \mathrm{~mm}$, whereas, in the mature rabbit, a commonly used experimental animal, it has a thickness of only approximately $300-400 \mu \mathrm{m}$, while, in dogs, the thickness is about
$0.6-1.3 \mathrm{~mm}$ [18]. In larger animals, the thickness of the articular cartilage layer is about $0.7-1.5 \mathrm{~mm}$ in sheep and goats, $1.5-2.0 \mathrm{~mm}$ in horses, and $1-2 \mathrm{~mm}$ in miniature pigs (pers. comm., Professor Tzong-Fu Kuo, Superintendent of the National Taiwan University Veterinary Hospital). Because of these limitations of animal studies, it is necessary to develop a large animal defect model which is better able to mimic the human condition than small animal models. In addition, systemic control experiments are required in order to draw unequivocal conclusions [8]. In our study, we used miniature pigs, as these are large animals with a body weight similar to humans and with a similar cartilage thickness. If tri-copolymer-based tissue engineering could be shown to predictably restore a functional articular surface in animals, it would then be reasonable to perform a clinical trial.

The results showed that a good gross appearance was only seen in those condyles treated with either tissue engineering or auto-transplantation. Spontaneous repair of an OC defect did not fully restore the smooth articular surface. The gross appearance of the condyles treated with auto-transplantation was slightly better than that of the FT 
and OC tissue-engineered condyles, but statistically there was no difference. The gross appearance of condyles treated with $\mathrm{OC}$ tissue engineering and auto-transplantation was statistically better than that in the spontaneous repair group $(p<0.05)$, while that of condyles treated with FT tissue engineering showed a trend to be better than that in the spontaneous repair group $(p=0.0897)$. There was no significant difference in gross appearance between the FT and $\mathrm{OC}$ tissue engineering groups.

However, although the spontaneous repair groups had a worse gross appearance (nine condyles with a poor gross appearance), five poor results were also seen in the tissue engineering groups and six in the auto-transplantation group. In the 15 pigs in the study and internal control groups, $41.7 \%$ of the condyles showed poor results, $30 \%$ good results, and $28.3 \%$ fair results. There were no good results in the spontaneous repair group. The high percentage of poor results may be due to several reasons. Firstly, we used post-operative antibiotic gel rather than pre- and post-operative intravenous antibiotics which may have allowed intra-articular infection and subsequent scarring and osteoarthritic changes. Secondly, the pigs were allowed to exercise freely after the operation, without any protection and rehabilitation, which may have caused post-traumatic osteoarthritis. Thirdly, we used allogenous cells and it is possible that there may have been an immune reaction and rejection, although the literature reviews suggest this is very unlikely [19-23].

The results for the external control group showed that scaffold alone (without cell seeding) can have a complex influence on the spontaneous repair process. The repaired tissues were irregular, bizarrely shaped, and mixed with different cellular types. The quality of the repair tissues seen using scaffold alone was worse than that with spontaneous repair. This phenomenon also implies that the cell source (the periosteum covering the scaffold) was not adequate for effective tissue repair.

Autogenous OC transplantation gave good reconstruction and integration into subchondral bone, as reported previously [24]. Tissue engineering therapy with chondrocytes for an OC defect was unable to recreate the subchondral bone, a result compatible with a previous report [23], whereas tissue engineering therapy for an FT defect was able to restore the subchondral bone. This might be partly due to the preservation of intact subchondral bone when the defect was created. Mesenchymal stem cells and growth factors can also come from the FT articular defect and may contribute to the good integration into subchondral bone in condyles treated with FT tissue engineering. In terms of the reconstruction of the $\mathrm{OC}$ junction, auto-transplantation and condyles treated with FT tissue engineering were better than OC tissue engineering or spontaneous repair groups.

Siebert et al. [25] investigated the healing of autogenous OC grafts and found no integration of the cartilage interface after 3 and 6 months, although the osseous integration was already complete after 3 months, results compatible with our own. The tissue engineering-treated and spontaneous repair condyles showed better integration into host cartilage. Mesenchymal stem cells from the defect sites, the immature and developing status of the engineered tissue, and spontaneous repair tissue may all contribute to the better integration. The auto-transplanted material consisted of mature cartilage tissue, which contained large amounts of GAG and mature matrix, which may interfere with integration into host cartilage, and poor integration of articular cartilage can lead to degeneration [24].

The histology results for the external control group showed that there was some capacity for self-repair of an FT defect (the average age was lower than in than study/ internal control group) and that scaffold material had an adverse effect on spontaneous repair, such as destruction of the subchondral bone plate, poorer matrix formation, and interference with integration to host cartilage. However, this adverse effect could be overcome by seeded cells. Spontaneous repair of an OC defect was compromised, possibly due to the uneven distribution of mechanical force, and if the defect was filled with scaffold and covered with periosteum, the repair result was better. This indicates that filling the OC defect is better than leaving it unfilled and that, if the scaffolds are seeded with cells, the results are even better.

Since this was an animal study, some methodological limitations have to be addressed. It should be stressed that the pigs were returned to full activity immediately after operation, which may have caused post-traumatic osteoarthritis. In humans, a gradual increase in weight bearing coupled with continuous passive motion $[26,27]$ would be a better protocol for articular regeneration. The cells used in this study were not autogenous cells, but were obtained from the slaughterhouse and the quality of these allogenous chondrocytes could not be controlled. We have no information on the sex, age, or weight of the donor pigs. These cell sources also have the potential to carry bacteria, increasing the risk of infection and also increase the risk of immune rejection. Many cartilage research studies have used a force-displacement test to test the mechanical property of the regenerated cartilage [e.g., 28,29]. In our study, no mechanical study was performed. However, the biomechanical properties of articular cartilage are complex and not yet fully understood and the biomechanical properties needed for the successful tissue-engineered cartilage construct are not yet known. Currently, there is no standardized biomechanical test for normal articular cartilage or tissue-engineered cartilage constructs [30]. However, the histology, morphology, and evaluation score is likely to be predictive of its functionality and durability [31]. The mechanical properties of engineered cartilage are very important for functional tissue engineering and we plan to develop a mechanical test to evaluate these in future studies. The large area of the repaired defect in our study may require the development of a special instrument for mechanical testing, rather than a small area indentation test. Immunohistochemical and molecular biological 
analyses are also important in defining the phenotypic character of the tissue in the repair site, but we will leave these studies until after we have optimized the repair method. Moreover, the ICRS Histological Endpoint Committee does not recommend immunohistochemical and proteoglycan staining in their present evaluation protocol, as there is currently no consensus on the optimal staining methods [31].

\section{Conclusion}

In conclusion, tri-copolymer scaffold supported allogenous chondrocyte transplantation in a miniature pig animal study. However, because of the limited availability of autogenous and allogenous chondrocytes in clinical practice, we are currently investigating the use of mesenchymal stem cells for the repair of osteochondral articular defects.

\section{Acknowledgments}

The authors were supported by Grant FEMH 92-D-022 from the Far Eastern Memorial Hospital and Far Eastern Medical Foundation and by Grant NSC 93-2321-B-002002 from the National Science Council. The authors thank Dr. Thomas Barkas, Kilbarchan, Johnstone, UK, for editing manuscript.

\section{References}

[1] Solchaga LA, Goldberg VM, Caplan AI. Cartilage regeneration using principles of tissue engineering. Clin Orthop 2001;391S:S161-70.

[2] Athanasiou KA, Shah AR, Hernandez RJ, LeBaron RG. Basic science of articular cartilage repair. Clin Sports Med 2001;20(2): $223-47$.

[3] Scully SP, Lee JW, Ghert PMA, Qi W. The role of the extracellular matrix in articular chondrocyte regulation. Clin Orthop 2001;391S: S72-89.

[4] Chang $\mathrm{CH}$, Liu HC, Lin $\mathrm{CC}$, Chou CH, Lin FH. Gelatin-chondroitin-hyaluronan tri-copolymer scaffold for cartilage tissue engineering. Biomaterials 2003;24:4853-8.

[5] Gillogly SD, Voight M, Blackburn T. Treatment of articular cartilage defects of the knee with autologous chondrocyte implantation. J Orthop Sports Phys Ther 1998;28(4):241-51.

[6] Gilbert JE. Current treatment options for the restoration of articular cartilage. Am J Knee Surg 1998;11:42-6.

[7] Mitchell N, Shepard N. The resurfacing of adult rabbit articular cartilage by multiple perforations through the subchondral bone. J Bone Jt Surg 1976;58A:230-3.

[8] Hunziker EB. Articular cartilage repair: basic science and clinical progress. A review of the current status and prospects. Osteoarthritis Cartilage 2002;10:432-63.

[9] Maroudas A. Physiochemical properties of articular cartilage in adult articular cartilage. 2nd ed. Kent, UK: Pitman Medical Publishing Co.; 1979. p. 215-90.

[10] Mitchell N, Shepard N. Healing of articular cartilage in intraarticular fractures in rabbits. J Bone Jt Surg Am 1980;62:628-34.

[11] Wakitani S, Goto T, Pineda SJ, Young RG, Mansour JM, Caplan AI, et al. Mesenchymal cell-based repair of large, full-thickness defects of articular cartilage. J Bone Jt Surg Am 1994;76(4):579-92.
[12] Pineda S, Pollack A, Stevenson S, et al. A semiquantitative system for histologic grading of articular cartilage repair. Acta Anat (Basel) 1992;143:335.

[13] Shapiro F, Koide S, Glimcher MJ. Cell origin and differentiation in the repair of full-thickness defects of articular cartilage. J Bone Jt Surg Am 1993;75(4):532-53.

[14] Lu L, Zhu X, Valenzuela RG, Currier BL, Yazemski MJ. Biodegradable polymer scaffolds for cartilage tissue engineering. Clin Orthop 2001;391S:S251-70.

[15] Bostman OM, Pihlajamaki HK. Adverse tissue reactions to bioabsorbable fixation devices. Clin Orthop 2000;371:216-27.

[16] Breinan HA, Hsu HP, Spector M. Chondral defects in animal models: effects of selected repair procedures in canines. Clin Orthop 2001(391 Suppl):S219-30.

[17] Buckwalter JA. Evaluating methods of restoring cartilaginous articular surfaces. Clin Orthop 1999(367 Suppl):S224-38.

[18] Hunziker EB. Biologic repair of articular cartilage. Defect models in experimental animals and matrix requirements. Clin Orthop 1999 (367Suppl):S135-46.

[19] Kawamura S, Wakitani S, Kimura T, Maeda A, Caplan AI, Shino K, et al. Articular cartilage repair: rabbit experiments with a collagen gel-biomatrix and chondrocytes cultured in it. Acta Orthop Scand 1998;69:56-62.

[20] Frenkel S, Toolan B, Menche D, Pitman M, Pachence J. Chondrocyte transplantation using a collagen bilayer matrix for cartilage repair. J Bone Jt Surg 1997;79B:831-6.

[21] Grande DA, Singh IJ, Pugh J. Healing of experimentally produced lesions in articular cartilage following chondrocyte transplantation. Anat Rec 1987;218:142-8.

[22] Katsube K, Ochi M, Uchio Y, Maniwa S, Matsusaki M, Tobita M, et al. Repair of articular cartilage defects with cultured chondrocytes in Atelocollagen gel. Comparison with cultured chondrocytes in suspension. Arch Orthop Trauma Surg 2000;120:121-7.

[23] Wakitani S, Kimura T, Hirooka A, Ochi T, Yoneda M, Yasui N, et al. Repair of rabbit articular surfaces with allograft chondrocytes embedded in collagen gel. J Bone Jt Surg Br 1989;71:74-80.

[24] Tibesku CO, Szuwartn T, Kleffner TO, Schlegel PM, Jahn UR, Van Aken $\mathrm{H}$, et al. Hyaline cartilage degenerates after autologous osteochondral transplantation. J Orthop Res 2004;22:1210-4.

[25] Siebert Ch, Miltner O, Schneider U, et al. Healing of osteochondral grafts in an ovine model under the influence of bFGF. Arthroscopy 2000;19:182-7.

[26] O'Driscoll SW, Keeley FW, Salter RB. The chondrogenic potential of free autogenous periosteal grafts for biological resurfacing of major full-thickness defects in joint surfaces under the influence of continuous passive motion. An experimental investigation in the rabbit. J Bone Jt Surg Am 1986;68(7):1017-35.

[27] O'Driscoll SW, Keeley FW, Salter RB. Durability of regenerated articular cartilage produced by free autogenous periosteal grafts in major full-thickness defects in joint surfaces under the influence of continuous passive motion. A follow-up report at one year. J Bone Jt Surg Am 1988;70(4):595-606.

[28] Carey J, Small CF, Pichora DR. In situ compressive properties of the glenoid labrum. J Biomed Mater Res 2000;51:711.

[29] Barker MK, Seedhom BB. Articular cartilage deformation under physiological cyclic loading - apparatus and measurement technique. J Biomech 1997;30:377.

[30] Reinholza GG, Lu L, Saris DBF, Yaszemskia MJ, O'Driscolla SW. Animal models for cartilage reconstruction. Biomaterials 2004;25:1511-21.

[31] Mainil-Varlet P, Aigner T, Brittberg M, Bullough P, Hollander A, Hunziker E, et al. Histological assessment of cartilage repair: a report by the histology endpoint committee of the international cartilage repair society (ICRS). J Bone Jt Surg 2003;85-A (Suppl 2):45-57. 